\title{
ECOS DE JUSTICIA: ENTRE LA ESCRITURA Y LA ORALIDAD
}

\author{
SEbASTIÁn Rodríguez CÁRdenAS ${ }^{1}$
}

\begin{abstract}
RESUMEN: Con ocasión de la tendencia a la unificación de un sistema procesal oral y acusatorio en Colombia - relativamente reciente en contraste con el consolidado de su historia procesal -, este ensayo busca poner de relieve las bases filosóficas y literarias que subyacen a la aparente pugna entre la escritura y la oralidad, develando la pregunta subrepticia por la validez de las normas jurídicas, así como sus manifestaciones como modelos de coacción social. Por tanto, se estudian algunos relatos fundacionales de la vivencia de la ley como mandato escrito y como mandato oral a fin de analizar, posteriormente y desde la perspectiva de Foucault, el sistema jurídico de la antigua Grecia y el nacimiento de una oralidad contemporánea estructurada a partir del texto escrito.
\end{abstract}

PALAbRas Clave: oralidad primaria; oralidad secundaria; nomos; thesmós; leyes no escritas; derecho colombiano.

\section{PROEMIO}

Hubo un tiempo en que la humanidad no sabía escribir. Hubo también un tiempo en que el Derecho pareció olvidar dicha verdad, de forma tal que sólo las palabras escritas gobernaron el mundo de las relaciones jurídicas. Ese tiempo parece estar terminando.

El advenimiento de la oralidad en la justicia civil se une a las incursiones que en este campo hicieron las jurisdicciones laboral y penal. El derecho avanza (¿o regresa?) al mundo de la palabra hablada, y con este desplazamiento recrea los problemas de un derecho ritual que no puede entender la ley como un simple pronunciamiento escrito, sino como un ente vivo dotado de trascendencia que, a través del lenguaje, modifica el mundo.

1 Abogado de la Universidad de Caldas (UCaldas). Estudiante de Maestría en Teoría Jurídica y Política - MA Legal and Political Theory - de la University College London (UCL). Londres, Reino Unido. E-mail: sebastian.rodriguezcar@gmail.com 
Lo que me propongo con este escrito es mostrar, ante todo, que la tensión entre escritura y oralidad no da cuenta de una simple oposición frontal entre uno y otro sistemas, sino que, bajo dicho enfrentamiento, se mueven subrepticiamente un sinnúmero de peripecias que contribuyen a alimentar el caos que constituye la conceptualización del Derecho. Más aún, quisiera mostrar que el problema no es realmente novedoso, y que bajo su estudio pueden encontrarse razones de peso para asumir posturas en torno a los problemas de la vigencia de la ley y su interpretación.

\section{TABLAS DE LA LEY Y LEYES NO ESCRITAS}

La actual tensión entre oralidad y escritura se manifiesta en el mundo jurídico a través de la intrincada oposición que existe entre leyes escritas y leyes no escritas. Sin embargo, esta pugna no es reciente y el problema se encontraba ya vigente en la Grecia arcaica, así como en la tradición judeocristiana plagada de paradojas que se mueven entre la palabra hablada y la palabra escrita. Será necesario comenzar por estas manifestaciones del problema para comprender lo que subyace a la aparente lucha que se surte en la actualidad, en torno a la implementación de un sistema oral en un ordenamiento que, hasta hace muy poco, se caracterizaba por la veneración del sistema escrito.

El relato judío de los diez mandamientos es un buen lugar para comenzar.

Moisés, tras sacar a su pueblo de Egipto, llega al monte Sinaí donde se dispone a escuchar las leyes que dios va a proferir en virtud del pacto de la alianza. La promulgación de las leyes, en la forma del decálogo, se realiza en un principio, de forma oral: "En seguida pronunció el Señor todas estas palabras" (Éxodo 20, 1).

No obstante, una vez se termina el ritual de la promulgación del decálogo, dios se dirige exclusivamente a Moisés y le otorga un gran número de normas en torno a los delitos, la justicia y las celebraciones religiosas, para que posteriormente sean repetidas y escritas por Moisés para la totalidad del pueblo. Una vez hecho esto, dios ordena a Moisés subir 
en solitario al monte Sinaí donde las tablas de la ley son escritas "por el dedo de Dios" (Éxodo 31, 18)².

El poder de dictar las leyes recae en la divinidad, sin embargo, la forma en la que dicha ley mana del poder supremo sufre una mutación sustancial. El paso de la oralidad a la escritura puede justificarse con base a unos argumentos netamente pragmáticos: por un lado, la ley escrita es visible para todos, por lo que nadie puede excusarse en su desconocimiento; por otro lado, la ley escrita no puede borrarse y sus mandatos están llamados a perdurar en el tiempo. Estas justificaciones serán más que suficientes para mantener un sistema jurídico escrito en un gran número de ordenamientos, pero no explican el porqué de la presencia oral primigenia.

En efecto, si la ley escrita no puede borrarse y está a la vista de todos, la promulgación oral no es más que un ritual superfluo del que puede prescindirse, y sin embargo, el dios judío no prescinde de él.

En realidad el ritual no es contingente, pues el hecho de que sea dios, y no Moisés, quien pronuncie las palabras de la ley resulta ser una justificación apropiada para el papel subyugante que implica toda imposición de la ley.

Esto es evidente puesto que las palabras que provienen directamente de la boca de dios resultan aterradoras para el pueblo, al punto de solicitar a Moisés que funja como intermediario entre la ley y sus destinatarios, pues las palabras de dios son tan terribles que los hombres temen que acaezca sobre ellos la muerte a causa de ellas (Éxodo 20, 18-19). A pesar de acceder dios indirectamente a la petición, y llamar ulteriormente a Moisés para que suba a presenciar por sí mismo la escritura de las tablas, la justificación se mantiene imperturbable en el relato bíblico: "Respondió Moisés al pueblo: No temáis, pues el Señor ha venido a fin de probaros, y para que su temor se imprima en vosotros, y no pequéis" (Éxodo 20, 20). Y posteriormente: "Dijo además el Señor a Moisés: Esto dirás a los hijos de Israel: Ya habéis visto cómo yo os he hablado desde el cielo" (Éxodo 20, 22).

Lo que se oculta tras la ley oralmente pronunciada no es otra cosa que la autoridad real con la cual dios ejerce su soberanía, la demostración de su

\footnotetext{
${ }^{2}$ El tema se repite en Éxodo 32, 15-16: "Entonces Moisés bajó del monte, trayendo en su mano las dos tablas de la ley escritas por ambas partes y labradas por Dios, así como era también de la mano de Dios la letra grabada en ellas".
} 
poder supremo de otorgar leyes y, dicho sea de paso, de disponer de la vida de su pueblo mancipado. Desde esta perspectiva, la escritura no es más que la técnica a través de la cual las palabras pronunciadas por dios, que constituyen normas por sí mismas, se inscriben en la consciencia del pueblo que debe obedecerlas. La escritura facilita la introyección de la ley, pero no constituye un requisito sine qua non para que la ley sea aplicada, para que surta efectos. Tanto es así, que las tablas que contenían los mandamientos fueron destruidas por Moisés - al ver al pueblo adorar a un becerro de oro -, y dios le otorgó unas tablas nuevas con la reiteración del decálogo (Éxodo $34,28)^{3}$, sin que ello implicara una derogación de los mandatos pronunciados oralmente.

Ahora bien, la tensión entre escritura y oralidad no culmina en este punto. George Steiner resalta que el acto de escritura de la ley define al pueblo judío como un pueblo del libro que, a falta de un territorio firme sobre el cual acentuarse, pervive a través de los comentarios talmúdicos:

[La] reescritura del segundo juego de tablas hace de la ley en el judaísmo una textualidad, un acto, un escrito y un prescrito que hay que venerar, interpretar, comentar y aplicar en un diálogo incesante entre la letra escrita y sus lectores. Se trata verdaderamente de legislación, si la etimología nos permite unir aquí lex a legere. [...] Nuestra verdadera patria no es un trozo de tierra rodeado de alambradas o defendido por el derecho de las armas; toda tierra de este género es perecedera y precisa de la injusticia para sobrevivir, NUESTRA VERDADERA PATRIA ha sido siempre, es y será siempre un texto (Steiner, 2007, p. 67-68).

La textualidad de la que habla el autor no es otra cosa que el predominio de la escritura, que se convierte en el elemento definitorio de la esencia judía, y cuya consulta y glosas constantes a la Torá permiten el reconocimiento y la unidad de un pueblo que, durante gran parte de su historia, fue sinónimo de diáspora. Así, la autoridad, representada por las palabras originarias no puede existir más que por el registro escrito en el que consta dicha autoridad ${ }^{4}$.

3 Más diciente todavía resulta el hecho de que el pueblo elegido pecase por adorar al becerro, cuando aún no contaban con las leyes escritas, sino sólo con el primer mandamiento que pronunció dios de viva voz: "No tendrás otros dioses delante de mí" (Éxodo 20, 3).

4 Aquí yace, según Steiner, la brecha que separa al cristianismo del judaísmo y del islamismo. Ver Steiner (2007, p. 71 y 82). 
La ley renueva su vigencia a través de la relectura que cada generación hace de ella, lo que implica que el texto escrito debe existir a falta de un renovado pronunciamiento divino, pues de lo contrario, la autoridad de la ley se perdería en una narración vaga e inestable, carente de fuerza vinculante. Esto obliga al pueblo judío, donde quiera que esté, a volcarse completamente hacia la escritura como la única forma de identidad nacional, que se erige como el único ordenamiento posible ante la verdad de la dispersión. Si el predominio fuese oral, como lo fue originariamente dada la autoridad que manaba de dios, la diseminación habría dado al traste con toda la comunidad religiosa desde sus inicios. La ley, al estar escrita, ha mantenido al pueblo judío en el seno de un ordenamiento coherente, pero, como efecto secundario, ha instaurado un régimen de tradiciones que dificultan la mutación de la comunidad para adaptarse a nuevas situaciones.

La pregunta irremisible en este punto, es esta: ¿́cuál de las dos escritura u oralidad - debe prevalecer?, pregunta a la cual subyace otra pregunta de rigor: ¿Debe alguna prevalecer? Para responder a estas preguntas no basta con el ejemplo traído a colación sobre el pueblo judío y habrá que extender el estudio hacia otras esferas.

La tragedia de Antígona representa otra ilustración ineludible de la tensión entre leyes escritas y leyes no escritas. En la tragedia de Sófocles, Antígona desea enterrar a su hermano Polinices quien batalló en contra de Tebas, pero, para hacerlo, se verá obligada a romper el edicto de Creonte nuevo rey de Tebas - que prohíbe dar sepultura a los traidores. La prohibición está extendida hacia toda la ciudad y está sancionada con la muerte.

Antígona, a pesar de la prohibición, da inicio a los ritos funerarios de Polinices y es capturada y llevada ante el rey. Ante la pregunta de Creonte sobre la veracidad de los hechos que se le imputan, Antígona acepta plenamente la acusación y, ante el cuestionamiento que se la hace sobre el conocimiento del edicto, Antígona confirma haberlo conocido pues había sido proclamado públicamente. La justificación que da para sus actos, ante la insistencia de Creonte, da cuenta de una pugna que sobrepasa las barreras de la escritura, y penetra en el campo de batalla entre derecho positivo y derecho natural: 
CREONTE. - ¿Y a pesar de ello, te atreviste a transgredir estos decretos?

ANTÍGONA. - No fue Zeus el que los ha mandado publicar, ni la Justicia (Diké) que vive con los dioses de abajo la que fijó tales leyes para los hombres. No pensaba que tus proclamas tuvieran tanto poder como para que un mortal pudiera transgredir las leyes no escritas (ágraphous nómous) e inquebrantables de los dioses. Éstas no son de hoy ni de ayer, sino de siempre, y nadie sabe de dónde surgieron (Sófocles, 2000, p. 93).

Ágraphous nómous: Leyes no escritas. La prohibición de dar sepultura a un hombre ${ }^{5}$ resulta ser contraria a los mandatos de los dioses que, a pesar de no estar consignados en ninguna grafía, parecen ser de conocimiento general, no sólo porque Antígona los invoca a su favor, sino porque el coro reacciona favorablemente ante dicha deprecación, a pesar del silencio que guardan ante la presencia del tirano (Sófocles, 2000, p. 95).

La tragedia culmina con la muerte de Antígona, a manos de su prometido Hemón - el hijo de Creonte - quien también empuña la espada contra sí mismo, razón por la cual Eurídice, la esposa de Creonte, se quita también la vida. Todo esto muy a pesar de que el rey reconoce su error y proclama que "lo mejor [será] cumplir las leyes establecidas por los dioses mientras dure la vida" (Sófocles, 2000, p. 118).

Las leyes no escritas de los dioses triunfan sobre los mandatos de los hombres, y con ellas, un iusnaturalismo temprano se nutre abogando por la prevalencia de la justicia, que se evidencia moralmente en la decisión acertada de inhumar a Polinices (¿quién no obraría como Antígona y daría sepultura a su hermano fallecido?). Este tema bastaría para un artículo propio, por lo que no puede ahondarse en él en este momento.

Ahora bien, es preciso notar que las leyes no escritas (ágraphous nómous) tampoco han sido pronunciadas oralmente (i!) como sí es el caso

5 A decir verdad, el relato no indica explícitamente que Creonte haya proclamado su edicto por escrito, pero es de suponer que así fue, en tanto las palabras de Antígona así lo dan a entender. 
de las tablas de la ley judaica. La supuesta lucha entre oralidad y escritura se desdibuja, y lo que queda es una proclamación escrita y un designio informe que carece de fundamento y que, por paradójico que sea, prevalece sobre el ordenamiento escrito y conflagra la tragedia para Creonte.

De acuerdo con lo anterior, lo que subyace al problema de la oralidad y de la escritura es un problema de vigencia normativa que, de hecho, no se resuelve en favor de ninguno de los dos sistemas. Es, ante todo, la expresión fundamental de una lucha irresoluta que no puede decidirse por ninguna de las dos facciones en tanto ambas representan beneficios y perjuicios paralelamente: las leyes pronunciadas oralmente se inscriben en los corazones de los hombres, pero requieren de una intermediación entre su fuente y sus destinatarios - volveré sobre esto enseguida -, mientras que las leyes escritas están abiertas a todos, pero no proveen una relación de imperatividad, lo que se evidencia en que sus mandatos pueden quebrantarse tanto físicamente (la ruptura de las tablas por parte de Moisés), como apelando a un orden superior (ágraphous nómous). No es sorprendente que el problema de la vigencia siga preocupando al derecho aún milenios después, y quizás aquí se halle un germen inexplorado que pueda nutrir la rivalidad entre derecho positivo y derecho natural.

Pero eso no es todo. El problema de la vigencia normativa va acompañado por un problema de intermediación o de interpretación.

Así, en Antígona, la ley divina no puede conocerse dado que "nadie sabe de dónde surgió" y nunca ha sido pronunciada, ni de forma escrita ni de forma oral, por lo que requiere de un intermediario para alcanzar su destino, y dicho papel lo cumple el adivino ciego Tiresias. En el marco de la tragedia, Tiresias advierte al rey sobre el craso error que está cometiendo al condenar a una muerte insepulta a Polinices, y a una muerte lenta a Antígona. Su ceguera no es fortuita, Tiresias es incapaz, como todos, de leer los mandatos de los dioses porque no están escritos, pero en compensación, es capaz de descrifrar en los augurios de las aves sangrantes y en los sacrificios fallidos, la tragedia que está a punto de acaecer sobre Creonte. En este caso, los dioses no pronuncian palabras, sino que envían designios para que sean interpretados por el adivino, que se ve en la obligación de comunicárselos al rey. 
En contraste, Moisés resulta ser el intermediario de la ley una vez las palabras de dios habían infundido en los hombres temor y sumisión. De aquí se sigue una antítesis singular: mientras que en el relato del Éxodo la ley está doblemente proclamada - verbalmente por la voz de dios y por escrito mediante las tablas -, en el caso de Antígona la ley está doblemente oculta - los dioses han guardado silencio y sólo se comunican a través de manifestaciones oscuras que requieren de un intérprete. La intermediación, no obstante, permanece incólume, sin importar si las leyes están o no a la vista de todos.

Sería díficil, cuando no imposible, establecer un símil entre los intermediarios de la ley divina (Moisés y Tiresias) y los jueces en los ordenamientos jurídicos contemporáneos, no sólo por cuanto el legislador no cuenta en la actualidad con un status divino, sino también porque la figura del juez en estos relatos es difusa. No obstante, puede aventurarse si no un símil, por lo menos un vínculo.

En el caso de Moisés, éste designa a los hombres firmes y temerosos de dios como jueces (Éxodo 18, 21) antes de subir al monte Sinaí para recibir las palabras de la ley directamente de $\operatorname{dios}^{6}$. A pesar de la designación, Moisés se reserva para sí la facultad de juzgar en última instancia: "y las causas más graves las remitían a Moisés, juzgando ellos solamente las más fáciles" (Éxodo 18, 26). Este lugar privilegiado se justificará con la confirmación de Moisés como el intermediario entre dios y su pueblo, rol que cumplía desde un principio, pero que ahora se ve revestido por un bálsamo de legalidad que le confiere el poder de decidir sobre la suerte de los hombres, sin lugar a yerro y de acuerdo a la voluntad manifiesta de dios.

Luego, Moisés se convierte en el juez del pueblo, no por su capacidad de escuchar directamente a dios, sino por tener en su poder las tablas de la ley, así como por tener el poder de regresar a ellas cuando el pueblo así lo requiera (Deuteronomio 5 y 10). En otras palabras, dado que el pueblo como conjunto se negó a escuchar las palabras de la ley, ahora el privilegio

6 Para cualquier persona medianamente formada en nuestra idea de derecho contemporánea esto resultará ser un absurdo: si las leyes aún no han sido promulgadas, ¿sobre qué bases habrían de juzgar estos hombres?. No pretendo decir que deban juzgarse bajo las mismas bases ambos sistemas, pero es singular en el plano simbólico que la pregunta no parece incomodar a Moisés, ni mucho menos a la comunidad del pueblo elegido. 
de pronunciarlas se ve reducido a la persona de Moisés y sus delegatarios. Esto significa que, al igual que los jueces en la actualidad, Moisés cumplía un papel de acercamiento entre el texto legal y la vida real, entre el mandato formal y los hechos del mundo, convirtiéndose él mismo en un juez por el conocimiento y la reproducción del texto legal.

Algo similar sucede con Tiresias. La ley de Creonte no presenta oscuridad alguna, pues se encuentra escrita y promulgada para el pueblo. Pero los mandatos de los dioses, que se encuentran ocultos entre las capas de la naturaleza, deben ser interpretados y pronunciados por un hombre en específico, pues los ciudadanos apenas si pueden intuir dichos mandatos. Tiresias es un juez en tanto revela el sentido de la ley divina a Creonte y a los ciudadanos de Tebas. Tiresias traduce las palabras subrepticias de los dioses en mandatos concretos, y por eso es, desde cualquier perspectiva, un intérprete, que aún cuando carece de jurisdicción propiamente dicha, produce efectos jurídico-trágicos en la esfera política de Tebas.

Así pues, dos visiones de la justicia: el acercamiento y la interpretación. Ambas encierran conflictos del lenguaje que implican ya sea la pervivencia de la tradición oral o escrita, ya sea la posibilidad de existencia de un derecho más allá de lo legislado. Sin embargo, existe en ambas visiones un lugar común: la figura del juez-profeta-adivino es una figura de élite y segregación. Aún cuando el edicto de Creonte es visible para todo el pueblo, aún cuando dios habla directamente a su pueblo para darle el decálogo de mandamientos, e incluso aún cuando las leyes no escritas pueden ser intuidas, sólo existen unos pocos que están llamados a conocer plenamente la ley, ya sea para el acto de dominación que implica la enseñanza y el acercamiento (Moisés recuerda el decálogo constantemente y exhorta a cumplir con el pacto de la alianza), ya sea para el acto de transformación que implica la interpretación (Tiresias transforma la decisión del rey de condenar a Antígona, tras haber extraído un significado trágico de los augurios), o bien sea, simplemente, para la ejecución de la sanción con que viene acompañada la norma (Antígona muere por incumplir un edicto vigente, $\mathrm{y}$ ni siquiera los dioses acuden en su ayuda ante tal infracción).

En todos estos ejemplos es visible cómo el Derecho está vedado para la esfera de los profanos, y es por dicha exclusión que requiere de un tejido 
intersticial que permita transmutar la fuerza pura de la ley en mandatos susceptibles de obediencia por parte de sus receptáculos. El vínculo que existe entre estos relatos contentivos de la tensión entre escritura y oralidad, y que subyace toda la problemática actual, es el del canal de comunicación que se halla entre el acto de proclamación legal, su vigencia normativa y la forma en que dicha proclamación impacta sobre los ciudadanos.

\section{UN PROBLEMA DE ANTAÑO}

Nuevamente: hubo un tiempo en que la humanidad no sabía escribir: "El homo sapiens existe desde hace 30 mil y 50 mil años. El escrito más antiguo data de apenas 6 mil años” (Ong, 2004, p. 12). Como puede verse, la comunicación oral precede por mucho a la comunicación escrita, sin embargo, el mundo actual no puede concebirse si no es a través de la palabra escrita, y además de la escrita, la palabra impresa y la palabra digital.

Parece que el sistema actual de comunicación ha aprendido a sobrevivir a través de la conjunción de estas tecnologías de la palabra (caligrafía, tipografía, etc.) - que tienen todas el mismo raigambre caligráfico - y la comunicación oral que pervive aún después de tanto tiempo. Sería erróneo, no obstante, hablar de absolutos en este contexto. $\mathrm{Si}$ bien la oralidad precede cronológicamente a la escritura, su adopción en los sistemas procesales no representa un abandono de la palabra escrita, por el contrario, y como se verá, cada palabra pronunciada oralmente tiene una gran deuda con la técnica de la escritura, y las pugnas históricas que se han surtido entre ambas formas de expresión enriquecen el lenguaje como un todo, y permiten que éste adquiera un cariz de elaboración comparable con el de la música, más antigua todavía.

$\mathrm{El}$ advenimiento de un sistema de justicia oral no puede entenderse únicamente a partir de principios constitucionales y legales creados en el seno de la contemporaneidad. Sus orígenes se remontan largamente en el tiempo, y exigen una relectura de los andamiajes normativos y sus fuentes, de forma tal que dicha implementación de justicia sea una verdadera conquista, y no simplemente la dulce nostalgia de un pasado que embriaga con su aroma seductor. Quisiera recordar ahora unos cuantos ejemplos de este pasado dotado de significación. 


\section{Oralidad, escritura y verdad}

Entre el sonido feral y pre-lingüístico, y los extensos tratados de derechos humanos, la distancia que existe parece insalvable. Sin embargo, es necesario comprender que las palabras, originalmente, eran reproducciones sonoras de las cosas del mundo. Basta con pensar en el primitivo sonido del agua en francés - eau -, o la designación lingüística de ciertos fenómenos a través del sonido que producen, como es el caso del Big Bang, para entender que dicha herencia no se ha perdido aún, y que persiste, literalmente, como un eco que llega desde la distancia. Este legado hace referencia a las culturales orales primarias, es decir, aquellas que no poseen conocimiento alguno de la escritura (Ong, 2004, p. 38). Es imposible imputarle a estas culturas cualquier interpretación visual de las palabras, pues para ellos, las palabras no son más que los sonidos que se pronuncian una y otra vez, pero que se pierden en la inmensidad del espacio de no ser retenidas por la memoria.

Así por ejemplo, en hebreo ${ }^{7}$ el término para designar palabra y suceso es el mismo: dabar (Ong, 2004, p. 39). Esta doble significación, además de ser preciosa en sí misma para cualquiera que tenga interés por el lenguaje, muestra con claridad el origen de las palabras como un acontecimiento del mundo, que sucede en un momento determinado y que no puede mantenerse. De esta forma, es claro que la consciencia sobre el carácter efímero de la palabra hablada ha existido desde un principio, su temporalidad evanescente ha sido una problemática desde antaño, por lo cual, la necesidad de permanencia impulsará inexorablemente a la consagración de la escritura como el arquetipo de la supervivencia del lenguaje.

Mientras tanto, la única forma de conocimiento es la memoria. En palabras de Ong: "Uno sabe lo que puede recordar" (2004, p. 40). En una cultura oral primaria, todo aquello que no pueda ser recopilado en la memoria no constituye más que un pasado difuso, un suceso ya inaccesible desde el momento en que el olvido entra en juego.

7 Como ya se vio, la cultura hebrea no es, ni mucho menos, una cultura oral primaria. No obstante, Walter Ong (2004) explica este vínculo desde la perspectiva de la enseñanza de la palabra sagrada, que es esencialmente oral y que corresponde al rabbi o maestro. 
No es accidental que la palabra griega para verdad sea aletheia. Según la mitología griega Lethe ${ }^{8}(\Lambda \grave{\eta} \theta \eta)$ es el nombre que recibe uno de los ríos que riega el Hades, el río del olvido. Beber de las aguas del Lethe significaba, para los muertos que caminaban a través de la cueva de Hypnos, olvidar su vida en la tierra (Falcón Martínez et al., 1986, p. 387). En una extraordinaria muestra de coherencia lingüística, la verdad para los griegos es la oposición al olvido producido por el Lethe, a-lêthés, literalmente, la verdad es un no-olvido. Así las cosas, el ejercicio de la búsqueda de la verdad es, ante todo, un intento por levantar el velo que opaca la posibilidad de recordar, un des-cubrimiento que se hace a través de la memoria. El suceso, la palabra, que una vez pronunciada se olvida, resulta inexistente para el mundo oral, y sólo existe aquello que se recuerda.

En Platón, la aletheia resultaría de una enorme importancia, no sólo porque, de acuerdo con su filosofía, el hombre procedía del mundo de las ideas que había olvidado y al que habría de regresar (des-olvidar, recordar, vencer al olvido para encontrar la verdad); sino también porque la escritura resultaría un obstáculo para la memoria, una forma de sucumbir ante el olvido y negarse al conocimiento de la verdad. Así, en el Fedro, Platón relata a un supuesto mito egipcio que vale la pena transcribir parcialmente, por cuanto consagra su opinión sobre la escritura:

Pero, cuando llegaron a lo de las letras, dijo Theuth: "Este conocimiento, oh rey, hará más sabios a los egipcios y más memoriosos, pues se ha inventado como un fármaco de la memoria y de la sabiduría". Pero él le dijo: [...] "Y ahora tú, precisamente, padre que eres de las letras, por apego a ellas, les atribuyes poderes contrarios a los que tienen. Porque es olvido lo que producirán en las almas de quienes aprendan, al descuidar la memoria, ya que, fiándose de lo escrito, llegarán al recuerdo desde fuera, a través de caracteres ajenos, no desde dentro, desde ellos mismos y por sí mismos" (Platón, 1988, p. 403).

Y culmina Platón refiriéndose a la falsa sabiduría que obnubila e impide el alcance de la verdad:

8 De acuerdo con la Teogonía de Hesíodo, el Olvido (Lehte) es hijo de la odiosa Eris quien adicionalmente dio a luz a la Pena (Ponos), al Hambre (Limos), al Dolor (Algos), así como a las Disputas (Hisminias), las Batallas (Macas), las Matanzas (Fonos), las Masacres (Androctasias), los Odios (Neikea), las Mentiras (Pseudologos), las Ambigüedades (Anfilogías), al Desorden (Disnomia), a la Ruina (Ate) y al Juramento (Horcos), "que mayor desgracia causa a los hombres sobre la tierra, cuando alguien voluntariamente comete perjuro" (Hesíodo, 2005, p. 39-40). 
No es, pues, un fármaco de la memoria lo que has hallado, sino un simple recordatorio. Apariencia de sabiduría es lo que proporcionas a tus alumnos, que no verdad. Porque habiendo oído muchas cosas sin aprenderlas, parecerá que tienen muchos conocimientos, siendo, al contrario, en la mayoría de los casos, totalmente ignorantes, y difíciles, además, de tratar porque han acabado por convertirse en sabios aparentes en lugar de sabios de verdad (Platón, 1988, p. 404).

Según estos pasajes, la escritura impide la consumación del proyecto platónico de la verdad. Sin embargo, una paradoja indeleble se yergue sobre la sentencia platónica en contra de la escritura: sus palabras sólo nos han llegado a través de la escritura, más aún, las palabras de su maestro, Sócrates, se habrían perdido para siempre de no ser por su reproducción caligráfica. La tensión entre oralidad y escritura se muestra como una bifurcación con igualdad de sacrificios: preferir la palabra hablada implica el sacrificio de la permanencia a favor de la verdad; mientras que preferir la escritura implica la renuncia a la verdad para favorecer la inmutabilidad de las palabras.

¿Qué tiene que ver todo esto con el mundo del Derecho? Pues bien, el problema de la aletheia, que se debate en el umbral entre escritura y oralidad, tiene dos implicaciones jurídicas evidentes que, curiosamente, se deciden por cada una de las vías anteriormente mencionadas.

En primer lugar, el problema de la ley. La ley no puede ser el suceso de la palabra que se evapora fugazmente si no es conservada en la memoria. La aletheia, en su sentido más literal, debe estar al servicio de la ley para que ésta no caiga en el olvido, para que sus palabras se reiteren cuando sea necesario. Ulteriormente, la escritura vencerá a dicha postura, y la ley quedará escrita como mecanismo de conservación y como muestra física de su inmortalidad.

En segundo lugar, el problema del testimonio. La percepción de un hecho requiere del mayor grado de a-letheia posible para ser posteriormente representado en el juicio. El valor del testimonio se mide casi que exclusivamente por la capacidad que el testigo tenga de recordar las circunstancias fácticas del aquello que presenció. En su voz, los hechos deben convertirse en palabras, y con base a su verdad/aletheia se erigirá el juicio al que contribuye. En palabras de Ong: 
Los testigos eran prima facie más creíbles que los textos, porque era posible cuestionarlos y obligarlos a defender sus afirmaciones, mientras que con los textos esto no podía hacerse (2004, p. 98).

La tradición jurídica del testimonio responde, aún hoy - y sobre todo en el derecho penal - a una capacidad de transmisión oral que tiene la máxima fuerza probatoria, y que se mantiene a raíz de esa posibilidad inherente de confrontación? 9

En los apartes siguientes retomaré la primera de estas cuestiones, la cuestión de la ley. La segunda cuestión, sobre el testimonio, quede para después.

\section{Thesmós}

De acuerdo con lo tratado hasta el momento, la ley representa un problema sustancial en lo que a escritura y oralidad se refiere.

Así, una sociedad exclusivamente oral tendrá que confiar en la memoria para desentrañar el significado jurídico de las relaciones que se surten en su interior. $\mathrm{Al}$ respecto, dice Ong:

En las culturas orales, la ley misma está encerrada en refranes y proverbios formulaicos que no representan meros adornos de la jurisprudencia, sino que ellos mismos constituyen la ley. A menudo se recurre a un juez de una cultura oral para que repita proverbios pertinentes a partir de los cuales puede deducir decisiones justas para los casos sometidos a litigio formal (2004, p. 42).

No parece conveniente entrar a discutir, en este momento, la existencia de una jurisprudencia al interior de una cultural oral primaria. En realidad, el citado autor no es un jurista y procede de un sistema jurídico anglosajón que no posee la misma acepción de jurisprudencia que los sistemas de derecho continental europeo. Lo que importa realmente en este punto es entender el papel de la memoria en un derecho que se constituye a sí mismo, una y otra vez, como en un ritual. El juez, como portador de los proverbios de la ley, resulta ser una figura equivalente al sacerdote que,

9 Una discusión que aún no han surtido los especialistas en derecho probatorio es la de la verdadera validez del testimonio, en contraste con la real capacidad de percepción de los individuos. El derecho parece despreciar toda la evidencia científica que demuestra que el cerebro puede ser engañado con facilidad (ilusiones ópticas, por ejemplo), y sigue reconociendo en el testimonio la fuente más fidedigna de prueba, aún a pesar de la enorme posibilidad de engaño y de autoengaño que se da en términos de percepción. 
para invocar a su dios, debe pronunciar las fórmulas precisas. La diosa de la justicia requiere de un ritual de invocación que sólo los jueces conocen y que guardan en su pecho como un tesoro cuyo guardián es la memoria. Fallar en el pronunciamiento de las palabras de la ley es, a la postre, fallarle a la justicia.

En el derecho de la Grecia arcaica, estas fórmulas rituales que deben pronunciarse para acceder a la justicia están amparadas bajo el término

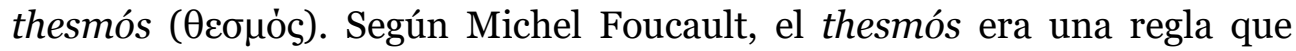
carecía de escritura - lo cual no implica que fuera puramente oral -, y que "se conserva en la memoria y es preciso recordarlo en la ocasión o el momento debido, cuando el acontecimiento o la circunstancia lo reclaman" (Foucault, 2012, p. 170). Naturalmente, Grecia no era una sociedad oral primaria, sin embargo llegó a contar con esta clase de procedimientos jurídicos que dependían de la memoria y que se erigían como una alehteia en su doble significación de verdad y de no-olvido.

De acuerdo con Foucault, el thesmós como palabra no funcionaba más que por la circunstancia en que debía ser pronunciado, lo que acentuaba su carácter esencialmente ritual, pues de enunciárselo en un momento inoporturno, la regla simplemente no surtía ningún efecto. Este proceso es semejante a la sentencia de un juez que carece de competencia. Sus palabras pueden estar de acuerdo con la ley, pero todo su discurso está desprovisto del locus en que debe ser pronunciado y, por consiguiente, está desprovisto también del poder necesario para modificar las relaciones jurídicas a que hace referencia. En uno y otro caso las palabras adolecen de nulidad, es decir, de inexistencia jurídica.

Ahora bien, el hecho de que el thesmós no estuviera escrito, y de que debiera guardarse celosamente en la memoria, tenía implicaciones de poder: "Los poseedores del discurso eran también los poseedores del poder y la riqueza" (Foucault, 2012, p. 171). Estas implicaciones de poder son tales que alrededor del ejercicio de la memoria existían individuos encargados de decir si tal o cual era el momento apropiado para para pronunciar la regla no escrita. Estos individuos eran llamados exégetas, y pertenecían a la propiedad familiar de la misma manera que el thesmós, eran legados inter familias (Foucault, 2012, p. 171). 
Foucault, acertadamente, llama la atención sobre un hecho que resulta extraordinario para los conocedores de las escuelas de interpretación jurídicas, sobre todo aquellos que practican devoción a la escuela de la exégesis: "Nótese de paso esta forma arcaica de la exégesis: que no está vinculada a la escritura, a la búsqueda de lo que ésta quiere decir, a su

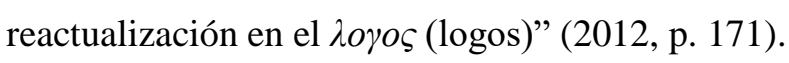

¡Una exégesis no escrita! La paradoja es increíble y, sin embargo, parece que la existencia misma del exégeta no está vinculada de forma alguna a la grafía, sino más bien a la interpretación de la circunstancia que amerita la aplicación de una regla ritual. Los exégetas están, en un principio, más cerca de Tiresias que de Moisés al interpretar el mundo que solicita el pronunciamiento de las palabras de la ley.

Ahora bien, el hecho de que la regla del thesmós pueda ser interpretada, aunque sea a partir de sus circunstancias, implica la posibilidad - me atrevería incluso a decir, la tentación ${ }^{10}-$ de que la norma se vea modificada. La sucesión de relatos orales no se hace con base en un referente estricto, sino que puede alterarse a conveniencia de quien transmite la regla oral o, inclusive, por descuido del tesorero de la palabra que se sumerge involuntariamente en las aguas del Lethe.

Una fijación meramente oral reporta grandes perjuicios para un ordenamiento jurídico con vocación de permanencia y ésta quizás sea la razón más pura y más pragmática por la cual el derecho contemporáneo es mayoritariamente escrito y no oral: los hombres pueden cambiar sus palabras, mientras que los textos, cualquier cosa que digan, la han dicho para siempre (Ong, 2004, p. 81).

Lo anterior no obsta para que en los ordenamientos jurídicos contemporáneos sobreviva algún componente que tenga como origen el ritual oral del thesmós con su marcado componente circunstancial. El juramento es un buen ejemplo de ello. Originalmente el juramento no se pensaba como un formalismo previo a la presentación del testimonio, pues de hecho constituía una prueba plena en la cual "se mostraba la solidaridad

10 Es el drama al que se enfrenta Raimundo Silva en la novela titulada Historia del cerco de Lisboa de José Saramago. El personaje, revisor de una editorial, sucumbe ante la tentación de anteponer un no a un relato histórico de sobra conocido: "los cruzados no auxiliarán a los portugueses a conquistar Lisboa". Toda la historia cambia con esta decisión, y si la historia puede modificarse caprichosamente, ¿qué puede esperarse de unas leyes ocultas en el juego entre el olvido y la memoria? 
social que un individuo era capaz de concitar, su peso, su influencia, la importancia del grupo al que pertenecía y las personas dispuestas a apoyarlo en una batalla o un conflito" (Foucault, 2003, p. 71-72). El juramento era, ante todo, una invocación verbal de la sociedad que el acusado efectuaba en el juicio, y que debía pronunciarse ritualmente de forma tal que surtiera algún efecto a su favor. Hoy en día el juramento no es más que la posibilidad de atribuir responsabilidad penal a quien incumpla con su deber de contribuir con la justicia, empero conserva su carácter eminentemente oral, además de llevar consigo un legado histórico ineludible que parece remontar al juicio a un derecho más allá de la ley, que no se ubica en unas máximas iusnaturalistas de ningún tipo, sino en la herencia indiscutible de la historia que pesa sobre le ejercicio de la justicia.

En el mismo sentido, los brocárdicos - designación correcta para las expresiones que se usan en el discurso jurídico actual y que provienen del latín - son indicios del rezago ritual ya mencionado. La costumbre que tienen los juristas de asignar nombres en latín a las figuras que están plenamente reguladas por el derecho colombiano - naturalmente en español - da cuenta de un saber privado que se transmite fuera de la ley, estrictamente hablando, y que constituye derecho a fuerza de repetición. Tal es el caso de la bona fide, que pertenece a la jerga de los civilistas y parece querer diferenciarse de la buena fe de consagración constitucional tan bien redactada en español; el caso de la capitis diminutio - término que confío sea utilizado únicamente como referente a un pasado ya lejano -; la causa petendi, en el derecho procesal; el imperativo del exequatur, en el ámbito del derecho internacional; así como el obiter dicta y la ratio descidendi en la jurisprudencia. Cómo olvidar, además, principios como el de pacta sunt servanda que expresa claramente, en español, el artículo 1602 del Código Civil Colombiano, o la maquiavélica fórmula de dure lex sed lex - que espero también se utilice para referir una concepción del derecho superada tiempo atrás.

Todas estas expresiones son muestras de un lenguaje que se esconde en la sombra de las leyes vigentes, y comunican, desde el pasado, el carácter místico del derecho que nos ha correspondido. 


\section{Nomos}

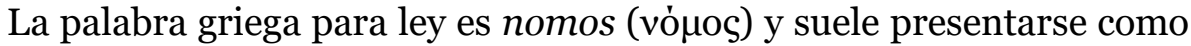
la superación del thesmós a fuerza de la inscripción caligráfica. En otras palabras, nomos es sinónimo de ley escrita.

No obstante, antes de equiparar nomos y ley, es necesario efectuar unos matices importantes si se quiere comprender la carga semántica con que está dotada la palabra. En realidad, traducir nomos como ley es altamente simplista, por lo que en este acápite intentaré aproximarme al concepto, para posteriormente vincularlo con el problema de la escritura.

Una lectura interesante de la palabra está dada por Carl Schmitt, quien, en su libro El nomos de la tierra, se ocupa del nomos como un concepto anterior a la ley: "El nomos, en su sentido original, sin embargo, es precisamente la plena inmediatitud de una fuerza jurídica no atribuida por leyes; es un acontecimiento histórico constitutivo, un acto de la legitimidad, que es el que da sentido a la legalidad de la mera ley" (Schmitt, 2002, p. 39).

De acuerdo con Schmitt, la palabra griega que desembocó en ley daba cuenta de una relación jurídica anterior - y mucho más profunda - a la proclamación de un mandato de tipo jurídico. Se trata del acto primigenio de ordenación que acaece con anterioridad al derecho. Es decir, antes de que cualquier norma jurídica fuese posible, era necesario la constitución de un ámbito en el cual dichas normas pudieran producirse. El acto de ordenar el mundo para ponerlo a disposición al derecho es lo que, para Schmitt, constituye el nomos. Es un "nomos de la tierra" en tanto el ámbito donde se ejerce el derecho requiere de un acto originario que transforme un lugar meramente habitable, en un lugar susceptible de normas y de relaciones jurídicas.

Hasta este punto entonces, el nomos es una manifestación que difiere de ley como difiere una causa de una consecuencia, y da cuenta de un significado que consiste en una ordenación primigenia, cuya dimensión espacial se determina en razón de un asentamiento físico que tal o cual población ejerce sobre el suelo, de forma tal que pueda gobernar sobre él y crear leyes con base a dicho territorio.

Para entender esta dimensión espacial del nomos sería posible establecer una analogía entre el nomos y la figura de la ocupación propia 
del derecho civil. De acuerdo con la definición del Código Civil colombiano, la ocupación es el acto por medio del cual "se adquiere el dominio de las cosas que no pertenecen a nadie" (Artículo 685). Pues bien, lo que intenta significar Schmitt es que en algún punto de la historia el mundo entero era un terreno absolutamente vacío de derecho, un territorio baldío en el que los imperativos jurídicos no cabían ni siquiera en la imaginación. En este punto de la historia un acto soberano de ocupación permitiría que los hombres se apropiaran de la tierra y ejercieran un derecho de dominio sobre ella, de tal forma que, a partir de este acto, se desprendiesen un sinnúmero de derechos y deberes correlativos al acto que reclama el dominio. En rigor, el dominio no existía en nadie antes de que operase el fenómeno de la ocupación. De manera análoga, para Schmitt, no existe ningún orden normativo anterior al nomos, ninguna vocación normativa anterior al establecimiento de un orden originario.

Dejando de lado la analogía, podría identificarse en esta concepción del nomos el establecimiento de la polis griega, que naturalmente no puede edificarse mediante un decreto, sino que todo decreto surge a partir de su edificación. En rigor, no existe ley griega alguna sin que no medie antes una polis. En un sentido análogo entiende Kelsen la diferencia entre el derecho subjetivo (aquel que se posee) y el derecho objetivo (el ordenamiento jurídico) tal y como está dividido en la lengua inglesa por la diferencia que existe entre right y law (Kelsen, 1986, p. 139) ${ }^{11}$.

Es claro que, para Schmitt, el nomos no puede ser el equivalente a una ley escrita. Es, de hecho, su condición de posibilidad, su matriz o, si se quiere, el acto que obliga para siempre a través del derecho.

Foucault establece una perspectiva disímil en cuanto a la lectura del nomos se refiere. En efecto, se trata de una ley escrita que se opone al thesmós, y que de hecho, más que escrita, está inscripta públicamente, se halla incrustada en la piedra para que cualquiera pueda mirarla (2012, p. 171). Pero no es exclusivamente eso. Foucault arguye que el nomos expresa también una ley no escrita, que se transmite a través de la educación como, según dice con base en Heródoto, son las leyes espartanas del ejemplo y de

\footnotetext{
11 Podría esgrimirse que se trata, a la postre, del establecimiento del Estado que precede a la ley. Creo que puede concederse con ciertas reservas que no es menester discutir aquí, no obstante, hay que evitar a toda costa caer en el juego del huevo y la gallina.
} 
los hábitos del honor (2012, p. 172). Podría pensarse en este punto que el nomos se ha asemejado al thesmós a través del proceso de aprendizaje e interiorización de las normas, sin embargo, la diferencia radica en que el aprendizaje es común, mientras que el thesmós se transmite como una forma de propiedad, literalmente, como un legado.

Pero allí no termina todo. Foucault extiende el significado de nomos hacia un tercer ámbito'i2: el logos ( $\lambda$ óyos). En este sentido, la ley, a pesar de ser intangible por cuanto está tallada en piedra, puede ser modificada a través de los debates y las votaciones (se trata, después de todo, de la democracia ateniense) que efectúen los ciudadanos en medio de un discurso público. Esto significa que "la ley está expuesta al discurso" (2012, p. 172), o lo que es lo mismo, que la ley está contenida en la palabra y que la inscripción que se haga de ella no es óbice para su modificación ${ }^{13}$.

El asunto se traslada entonces al problema de la pertenencia. Mientras que el thesmós era, como ya vimos, una forma de propiedad que significaba, a la par, una forma de poder; el nomos se presenta como una propiedad colectiva, lo que equivale a decir que no pertenece a nadie - esto en cada una de las formas presentadas. Vale la pena transcribir todo el aparte:

Inscripto en la piedra, presente en medio de todos sin que nadie tenga que formularlo, el vómos (nomos) ya no es pronunciado por nadie en particular, habla como por sí mismo, en su propio nombre [...] Contenido en la acometida o el juego del $\lambda$ óyos (logos), del discurso público, de la discusión, tampoco allí pertenece a nadie; pero todos pueden apropiárselo, someterse a él o modificarlo. Transmitido por la pedagogía, impuesto por ejemplos que se pierden en la noche de los tiempos, tampoco en este ámbito pertenece a nadie (Foucault, 2012, p. 173).

De esta forma, la oposición entre nomos y thesmós se da tanto en el plano ontológico como en el plano epistemológico, si se entienden cada una

12 Existe un cuarto ámbito en el que se asocia nomos con naturaleza. Prescindo de esta acepción por cuanto, de la lectura de Foucault, no se sigue que tenga una total coherencia con toda la temática que el autor viene trabajando.

13 Tanto es así, que de acuerdo con Foucault, cuando los griegos querían hablar de una ley intangible se referían a ella como thesmós, y no como nomos, pues este último podía cambiar a través del sistema democrático. Esto, muy a pesar de lo mencionado anteriormente sobre la posibilidad de modificar la palabra hablada. Aún cuando mantengo mi posición al respecto, considero necesario que el lector contemple esta forma de comprensión del thesmós. 
de las manifestaciones del nomos como la composición de un único concepto. Así, el nomos es ley escrita que sobrevive al paso del tiempo sin modificaciones involuntarias y que a la vez constituye un dominio público, irrefutable en cuanto a sus consecuencias. En sentido contrario, el thesmós pertenece a determinadas familias, y su sustancia está en la memoria que se presenta como verdad, que requiere de intérpretes calificados y circunstancias apropiadas para que surta efectos. En el plano epistemológico, el thesmós sólo puede conocerse a través del legado familiar, es una forma de herencia que, al igual que el dominio sobre bienes tangibles, otorga poder a quien lo posee y no debe decirse más que en el momento indicado. El nomos, en cambio, está abierto para quien sepa leer y escribir (esto constituye ya una exclusión, pero es un avance en contraposición a la figura del legado familiar), está a la vista de todos y sus palabras pronuncian, en todo momento y para siempre, aquello que constituye la ley: los mandatos se hacen perennes y la duda se despeja aún en detrimento de la memoria.

La pregunta que se suscita en este punto es, ¿dónde queda la definición de Schmitt en todo esto? Para responderla, es preciso introducir un nuevo concepto que complementa al nomos en Foucault. Este concepto es el de eunomía (cúvouía). El concepto trata, en principio, de una buena legislación, es decir, de un conjunto de leyes justas, conocidas y respetadas por todo el mundo; sin embargo, esta definición se queda corta en tanto, según Foucault, la eunomía existía mucho antes que el nomos. De lo que se trata realmente es de "un justo reparto de los bienes, una buena distribución de los gastos, los retornos y las distribuciones”(Foucault, 2012, p. 177) ${ }^{14}$.

Este justo reparto representa el momento previo a la construcción de la ley, y es, si se quiere, lo que el nomos es en Schmitt: Un orden previo del que surge la ley. Mientras que en Schmitt el nomos es ese orden establecido que posibilita la determinación de la soberanía (2009, p. 13), en Foucault el nomos es la consecuencia de la eunomía, una distribución de riquezas que permitió distribuir el poder político sin atentar contra el sistema económico

\footnotetext{
14 En este punto Foucault retoma un bagaje considerable que entiende el nomos como un ente cercano a nómisma (moneda), y que tiene implicaciones políticas y económicas que no pueden ser analizadas en este momento. Para ello remito a la lectura de las Lecciones sobre la voluntad de saber, donde el tema se extiende en torno al problema de la verdad y de la dominación.
} 
(2012, p. 175-182), y que da lugar a un concepto de ley que, además de estar escrito y a la vista de todos, permite un acceso generalizado al poder político ${ }^{15}$.

El extraordinario andamiaje conceptual que se erige detrás de la palabra nomos nos permite ahora acercarnos, propiamente, al problema de su escritura. Si bien en Schmitt no es posible hablar de un nomos escrito, sí es posible entender que dicha escritura no llega a tener existencia si no es bajo un orden pre-establecido que dota a las palabras de la ley de vigencia, de forma tal que puedan ser, o bien pronunciadas, o bien escritas. A partir de allí, es factible entrever que la superación del thesmós - como fórmula jurídica que implicaba propiedad privada y memoria - sí es posible a través del establecimiento de un nomos escrito que cumple con una función democrática (entiendo que no se trata de una cualidad benemérita, sino que esconde intereses económicos subterráneos) en la inscripción de la ley en piedra, posteriormente en bronce y en papel, para que todos los ciudadanos puedan acceder a ella. Esta inscripción efectuó la gran cesura entre el derecho ritual y el derecho procedimental, y permitió prescindir de la memoria para encontrar la verdad. El problema de la vigencia, que vimos anteriormente, permanece a pesar de todo.

El don de la permanencia que otorga la escritura puede expresarse de esta forma: "No hay manera de refutar un texto directamente. Después de una impugnación generalizada y devastadora, dice exactamente lo mismo que antes [...] Un texto que manifieste lo que el mundo entero sabe que es falso expresará la falsedad eternamente, siempre que ese texto exista. Los escritos son inherentemente irrefutables" (Ong, 2004, p. 81).

La ley que proscribe el homicidio seguirá intacta aún a pesar de que un hombre atente contra la vida de otro. Lo mismo sucede con los requisitos solemnes de la compraventa de bienes inmuebles, o con los pactos en contrario a los derechos laborales irrenunciables: la norma permanece incólume ${ }^{16}$. La virtud más excelsa de la escritura es que impide que las palabras puedan borrarse, ¿̇y qué, si no el Derecho, requiere que las

\footnotetext{
15 "Nómos [nomos] es el nombre que recibe un principio de distribución del poder que sirve para mantener (pero ocultarlos) los principios de atribución de las riquezas" (Foucault, 2012, p. 181).

16 Sobre la imposibilidad de una refutación real de la ley ver Ferrajoli (2008).
} 
cosas se mantengan imperturbables, como si estuvieran talladas en piedra? Sería impensable el ordenamiento jurídico actual si cualquier persona pudiera pervertir el contenido de una ley o de una sentencia, al igual que el de un contrato o el de la Constitución.

La escritura erradica estas dificultades. El nomos ejerce el máximo de su poder cuando las piedras, y no los hombres, cantan sus imperativos.

\section{Desmitificación de la escritura y Oralidad secundaria}

Hasta este punto, sería menester reconocer que el triunfo de la ley escrita es indiscutible, y que, si se quiere garantizar la estructuración de un orden jurídico abierto, que brinde seguridad normativa, y que no pueda ser alterado caprichosamente, entonces habría que evitar a toda costa cualquier manifestación oral en el mundo jurídico.

Quisiera refutar un pensamiento tal a través de dos argumentos. El primero de ellos pretende demostrar que la permanencia de la ley no se cumple en todos los casos y el segundo busca defender que la adopción de un sistema oral no implica el abandono de la escritura.

El hecho de que el nomos esté estrechamente vinculado al discurso y pueda ser modificado por este, implica ya, de suyo, una interferencia con los deseos de permanencia que nutren la consagración escrita de la ley. Esto, naturalmente, reporta un gran número de beneficios: el Derecho debe mutar, y para hacerlo, la escritura no puede ser realmente perpetua.

Sin embargo, existen casos en los que resulta deseable que la palabra escrita permanezca lo más intacta posible. El ejemplo más claro es el proveniente del derecho constitucional. De hecho, puede decirse que la Constitución es el reflejo más prístino de lo que se pretendía originalmente con la consagración de leyes en piedra ${ }^{17}$. Como es sabido, la Constitución supone un compilado de máximas y principios que, en algún punto, y por lo menos en el constitucionalismo contemporáneo, manaron del pueblo directamente y tienen el carácter de una égida contra la arbitrariedad estatal.

Dada su importancia, un gran número de constituciones posee procedimientos cualificados que deben seguirse estrictamente para llevar a

\footnotetext{
17 Este es literalmente el sentido de las llamadas cláusulas pétreas.
} 
cabo una reforma de su contenido. Lo que una gran mayoría de constituyentes persiguen con esto es establecer una cierta rigidez constitucional, que conserve y garantice un núcleo inmodificable de derechos y libertades, sobre los intentos de reducción que de estos puedan intentar los gobiernos. Igualmente, lo que se persigue es determinar problemas de fronteras, como un acto de soberanía, o brindarle estabilidad estructural al Estado para que no existan poderes con mayores atribuciones que otros.

Más allá de si debe o no existir rigidez en la reforma constitucional ${ }^{18}$, lo que me interesa es mostrar que la escritura no garantiza que dichos derechos y libertades se mantengan, ni tampoco así las fronteras o la estructura estatal. Se trata, en última instancia de un acto tentativo y simbólico que no está respaldado por una inmutabilidad real.

Antes de pasar a los ejemplos concretos, quisiera servirme de un corto ejemplo literario.

Bien conocido es el libro de George Orwell titulado Rebelión en la granja (Animal Farm). En él, los animales de una granja se sublevan ante la explotación de los humanos y establecen siete mandamientos que "serían inscritos en la pared [y] formarían una ley inalterable por la cual deberían regirse en adelante todos los animales" (2008, p. 68). Los mandamientos estaban encaminados a prohibir que los animales adoptaran cualquier comportamiento humano como beber alcohol, usar ropa o caminar en dos pies, entre otros. Los mandamientos concluyen así: "Todos los animales son iguales" (2008, p. 68).

Conforme la historia avanza, los cerdos, que no por azar son los líderes de la revolución animal, comienzan a adoptar los comportamientos que ellos mismos habían prohibido mediante los siete mandamientos, incluyendo la ingesta de alcohol y la caminata en dos pies. Al ver dichas actitudes, los demás animales se trasladan a la pared donde está inscrita la ley inalterable por la que se rigen todos los animales y lo que encuentran es la muestra más clara de la genialidad de Orwell:

TODOS LOS ANIMALES SON IGUALES PERO ALGUNOS ANIMALES SON MÁS IGUALES QUE OTROS (2008, p. 171).

18 Remito a un texto interesante sobre el tema: Laporta (2001). 
La supuesta seguridad que brinda la escritura no es más que una ilusión en el mundo contemporáneo. Cualquier estipulación de derechos, aún cuando tenga consagración constitucional, puede verse alterada o incluso subvertida en un abrir y cerrar de ojos, puesto que las piedras de la ley ya no existen y su materialidad se ha perdido a favor de su difusión. Tan pronto como la piedra fue reemplazada por el papel, la seguridad de la escritura perdió consistencia; y es que el acto simbólico de la talla pétrea implicaba, en sí mismo, un ritual de modificación que requería de la presencia de la ciudadanía y del consenso popular. Esta pérdida de consistencia se debe a que la sociedad actual no es una sociedad caligráfica, como lo fue la Grecia antigua, sino que es una sociedad digital y tipográfica en la que la modificación de los textos es la tarea más simple que existe ${ }^{19}$. Cualquier persona puede tener acceso a la infinidad de leyes, decretos, actos legislativos, etc. Todo esto es maravilloso porque amplía el espectro del poder político, pero no puede sostenerse con la idea falaz de la escritura como manantial de la seguridad jurídica.

Por fortuna, el núcleo duro de libertades permanece casi intacto, gracias al trabajo de la Corte Constitucional Colombiana - que no está, ni mucho menos, libre de máculas -, pero aún así, los actos legislativos promovidos por los distintos gobiernos han logrado penetrar en algunos artículos de la Constitución que se pensaron como insustituibles.

La deformación del artículo 48 es una muestra clara de una intromisión del gobierno en las garantías que ni siquiera la Constitución con su escritura protegida pudo conculcar: el Acto Legislativo 01 de 2005 introdujo 9 incisos, 2 parágrafos permanentes y 6 parágrafos transitorios al artículo 48 originalmente sancionado por la Asamblea Nacional Constituyente (i!), y aún existen quienes se creen puristas con referencia a la Constitución Política de 1991.

$\mathrm{Ni}$ siquiera es necesario que la reforma sea colosal, como lo fue la del artículo 48 anteriormente mencionado. El artículo 49, que consagraba originalmente el derecho a la salud, resultó siendo, de acuerdo con el Acto Legislativo 02 de 2009, una limitación al libre desarrollo de la personalidad - que no estuvo jamás ideado por el constituyente primario - que proscribe

19 De nuevo, la tentación de modificar las normas está presente a pesar del sistema escrito (ver nota 5). 
el uso o el porte de sustancias estupefacientes. El problema, naturalmente, no es el consumo en sí mismo, sino la inclusión de un constreñimiento a la libertad sin la aprobación popular.

Con estos ejemplos, tanto el literario como el constitucional, quiero demostrar que la escritura no es ya un sistema de seguridad que amerite su conservación a cualquier costo, sino que, de hecho, es una técnica que, si bien le será útil al derecho durante mucho tiempo, no puede ser la técnica imperante en todo lo que tiene que ver con el devenir jurídico de la actualidad.

Esto me lleva al segundo punto. La oralidad que se propone estatuir en la justicia hoy en día responde a una oralidad secundaria, es decir, aquella que proviene de una sociedad en donde la escritura se ha interiorizado a tal punto, que la forma en la que se habla está determinada por la estructura del texto escrito, y no depende de la memoria ni del sonido. Así,

Las personas que han interiorizado la escritura no sólo escriben, sino también hablan con la influencia de aquella, lo cual significa que organizan, en medidas variables, aun su expresión oral según pautas verbales y de pensamiento que no conocerían a menos que supieran escribir (Ong, 2004, p. 61).

Todo el Derecho que conocemos está cimentado en la palabra escrita. Esto no va a cambiar por la adopción de un sistema de justicia oral, antes bien, se verá nutrido por ambas corrientes y encontrará la superación de problemas tales como la lentitud y la ampulosidad, que plagan la administración de justicia aún en los tiempos que corren.

Se trata sí, de extirpar del sistema jurídico la idea de la escritura como una suerte de revelación insuperable que constituye per se, al Derecho, como si antes de la escritura el Derecho no hubiese sido posible: hay quien, aún hoy, entiende que positivismo y ley escrita son términos intercambiables. Éste equívoco ha persistido durante mucho tiempo y debe cesar. En realidad, la escritura no es más que una tecnología. Se trata de un complejo sistema de símbolos que se han utilizado para contener y transmitir, entre otras cosas, las palabras de la ley, puesto que brindaban el máximo de seguridad y confiabilidad. No obstante, esta tecnología parece sumergirse ante el advenimiento de una sociedad digital y mediatizada. El quid del asunto es reconocer que, tanto el video como el registro sonoro, 
son otras tecnologías, y cumplen la misma función conservadora que la escritura en tanto sean adoptadas por un mayor número de personas. Es innegable que este proceso se ha dado precipitadamente, en comparación con lo que tardó la humanidad en aprender a leer y a escribir, y puede significar que ambas tecnologías serán reemplazadas con mucha mayor presteza de lo que está siendo reemplazada la escritura ${ }^{20}$. Aún así, la posibilidad de que el derecho se extienda a las esferas de la palabra hablada como nunca lo ha hecho, no puede verse avasallada por la creencia absurda en una ley escrita e inmodificable que, en rigor, no existe desde hace mucho tiempo.

Tampoco hay que entender que el regreso a la oralidad implica un retorno al reino del thesmós. Como ya se dijo, el derecho ritual ha ido perdiendo su fuerza a pesar de que las estructuras lingüísticas se conserven en el escenario del juicio.

Por el contrario, el nomos no renuncia a la escritura, sino que la utiliza para inscribirse en un medio distinto que permite su dinamización. Cada paso hacia la oralidad secundaria es un avance que tiene lugar sólo en virtud a la escritura, y por eso no puede abandonarla nunca. El fin del sistema escritural no implica, pues, el fin del derecho, sino su renovación, a propósito de los problemas de vigencia y de interpretación que señalaba anteriormente.

Con respecto a este nuevo avance quisiera plantear una última reflexión: cuanto más bello resulta que nuestra sociedad, a falta de piedras donde tallar sus leyes, las inscriba en el aire como los dioses griegos lo hicieron en la naturaleza.

\section{REFERENCIAS}

FALCÓN MARTÍNEZ, C.; FERNÁNDEZ-GALIANO, E.; LÓPEZ MELERO, R. Diccionario de mitología clásica. Madrid: Alianza, 1986.

FERRAJOLI, L. Epistemología jurídica y garantismo. México D.F: Fontamara, 2008.

\footnotetext{
20 En ningún momento abogo por la obliteración de la escritura, por el contrario considero indispensable mantenerla como un tesoro que nos ha dado, además de derecho y filosofía, la literatura. Así mismo, es claro que la era digital no reemplaza las grafías en sí mismas sino únicamente su forma de consignación. La nostalgia por la palabra impresa, no obstante, pervive y lo hará para siempre.
} 
FOUCAULT, M. La verdad y las formas jurídicas. Barcelona: Gedisa, 2003.

FOUCAULT, M. Lecciones sobre la voluntad de saber: curso en el Collège de France (1970-1971). Buenos Aires: Fondo de Cultura Económica, 2012.

HESÍODO. Teogonía; Trabajos y días; Escudo; Certamen. Madrid: Alianza, 2005 .

LAPORTA, F. El ámbito de la constitución. España: Doxa, 2001

KELSEN, H. Teoría pura del derecho. México D.F.: Universidad Nacional Autónoma de México, 1986.

ONG, W. J. Oralidad y escritura: tecnologías de la palabra. México D.F.: Fondo de Cultura Económica, 2004.

ORWELL, G. Rebelión en la granja. Barcelona: Destino, 2008.

PLATÓN. Diálogos, III. Madrid: Gredos, 1988.

SCHMITT, C. El nomos de la tierra. Granada: Comares, 2002.

SCHMITT, C. Teología política. Madrid: Trotta, 2009.

SÓFOCLES. Antígona. Bogotá: Gredos, 2000.

STEINER, G. Los Logócratas. México: Fondo de Cultura Económica, 2007.

Lengua original: Español

Recibido: 08/05/16

Aceptado: 07/12/16 